\title{
Biopelículas como expresión del mecanismo de quorum sensing: Una revisión
}

\section{Biofilms like expression of quorum sensing mechanism: $A$ revision}

\author{
DÍAZ CABALLERO AJ* \\ VIVAS REYES R** \\ PUERTA L*** \\ AHUMEDO MONTERROSA M $* * * *$ \\ ARÉVALO TOVAR $\mathbf{L} * * * * *$ \\ CABRALES SALGADO $\mathbf{R} * * * * * *$ \\ HERRERA HERRERA $\mathbf{A} * * * * * * *$
}

\begin{abstract}
Díaz Caballero AJ, Vivas Reyes R, Puerta L, Ahumedo Monterrosa M, Arévalo Tovar L, Cabrales Salgado R, Herrera Herrera A. Biopelículas como expresión del mecanismo de quorum sensing: Una revisión. Av Periodon Implantol. 201 1; 23, 3: 195-201.
\end{abstract}

\section{RESUIMEN}

En la periodoncia moderna, el concepto de biopelículas viene en un progreso tan abrumador que la capacidad de discusión se hace necesaria y completamente indispensable, de forma que se pueda actualizar y cambiar de una idea de placa bacteriana a un concepto mucho más complejo, dinámico y de intercambio génico que lo que se viene estableciendo. Las biopelículas muestran una organización no al azar, con una forma de crecimiento y de sostenibilidad muy avanzada y estructurada que facilita la supervivencia de los patógenos incluidos dentro de estas formas de asociación.

El presente artículo es una revisión narrativa de los mecanismos de como el quórum sensing y las biopelículas se relacionan con las enfermedades periodontales que afectan a tantas personas en todas las latitudes a nivel mundial. Se exploran diversos conceptos y campos de investigación biomédicas con posibles aplicaciones a nivel experimental.

PALABRAS CLAVE: Periodoncia, biopelículas, quórum sensing, expresión génica, periodontitis, placa dental (Decs Bireme).

\section{SUMIMARY}

In modern periodontics, we must check continuously many concepts that are driving some time, which does not allow the progress and development of many structures of thinking in solving problems such as periodontal disease in all its various forms presentation. The concept of biofilms is in progress so overwhelming that the ability of discussion is completely necessary and indispensable, so that you can update and change a plaque idea to a concept much more complex, dynamic, and that genetic exchange what has been established to date. Biofilms are a non-random, is a form

*

$* *$

$* * *$

$* * * * *$

$* * * * * *$

$* * * * * * *$

Odontólogo. Universidad de Cartagena. Especialista en Periodoncia Universidad Javeriana. Magister en Educación Universidad del Norte. Estudiante Doctorado Ciencias Biomédicas. Universidad de Cartagena. Profesor Titular Universidad de Cartagena. Director Grupo de investigaciones GITOUC

Químico. Universidad del Valle. Máster en Química, Universidad del Valle. Doctor en Ciencias Universidad libre de Bruselas. Profesor Titular Facultad de Ciencias Exactas y naturales Universidad de Cartagena.

Químico Farmacéutico. Universidad de Cartagena. Magister en Ciencias Universidad Nacional, Bogotá. Doctor en Ciencias Biológicas, Pontificia Universidad Javeriana, Profesor Titular, Instituto de Investigaciones Inmunológicas de la Universidad de Cartagena.

Químico. Universidad de Cartagena. Estudiante de Maestría en Química Universidad de Cartagena.

Odontóloga. Universidad de Cartagena. Especialista en Periodoncia Universidad de Buenos Aires. Profesora Titular Universidad de Cartagena.

Odontólogo. Universidad de Cartagena. Doctor en Ciencias Odontológicas. Profesor invitado Universidad de Cartagena. Investigadora. Facultad de Odontología Universidad de Cartagena. Grupo de Investigaciones GITOUC.. 
of growth and sustainability quite advanced and structured to facilitate the survival of the pathogens included in these partnerships. This article is a narrative review, mechanisms such as quorum sensing, biofilms and the relationship of these with periodontal diseases that affect many people at all latitudes worldwide. It explores various concepts and research areas with potential application in biomedical experimentation level.

KEY WORDS: Biofilms, quórum sensing, gene expression, periodontitis, dental plaque (Mesh).

Fecha de recepción: 1 de junio de 2010.

Fecha de aceptación: 16 de junio de 2010.

\section{INTRODUCCIÓN}

Las biopelículas son estructuras complejas de asociación de microorganismos similares y de diferentes especies bacterianas, con el fin de organizarse en forma de un supra organismo con características superiores a las que presentan individualmente las bacterias (1).

El principio de la formación de una biopelícula se establece como parte de los procesos que se pueden presentar en el mecanismo conocido como quórum sensing (QS). Las bacterias mantienen una comunicación permanente entre ellas, dentro de los diferentes ambientes 0 microambientes donde permanecen y conviven. Los mecanismos de comunicación, le permiten reconocer cuando se alcanza el umbral o nivel de presencia, para desarrollar nuevas funciones, especialmente un comportamiento social, simbiótico y de permanente reconocimiento, útil para las tareas que adquieren en el mecanismo de QS (2).

En un tiempo a las bacterias se les percibía como organismos que rara vez interactúan entre ellas, con funciones aisladas, e individuales. Hoy se sabe que las bacterias llevan una vida muy social, en simbiosis, con la capacidad de desarrollar mecanismos y formas de comunicación (3). Esta manera de adaptarse a una vida en comunidad y capacidad de sociabilidad les confiere la potencialidad de detectar la densidad celular local y por consiguiente la oportunidad de desarrollar y coordinar los comportamientos de un grupo. Esta capacidad denominada detección de quórum o "quórum sensing", la desarrollan a través de la secreción y detección de las moléculas autoinductoras que se acumulan en un espacio dependiente de la densidad poblacional y del espacio de convivencia (4). Cuando las concentraciones de la molécula autoinductora o molécula señal, llegan a una determinada concentración, se activa un mecanismo de detección de quórum al cual responden las células, lo que permite a las bacterias, modular sus comportamientos, incrementar la eficacia y adecuación para el medio ambiente logrando una serie de beneficios que dependen de la presencia o ausencia de otras células o de ellas mismas (5). Las características de esa comunidad en condiciones de QS, desarrollan el control de detección de comunidad en la superficie, lo que incluye la posibilidad de lograr la fijación a los sustratos, la producción de polímeros extracelulares, la síntesis de biosurfactante, la esporulación, la competencia, la bioluminiscencia, la secreción de nutrientes, la síntesis de compuestos y la producción de factores de virulencia (6).

Existe una diversidad de situaciones y patologías, en las cuales las biopelículas tienen un papel predominante. Las bacterias tienen una vida social fascinante y diversa, dan muestra de un comportamiento coordinado y de grupo regulado por QS. Un ejemplo clave de comportamiento de estos grupos es la formación de las biopelículas, en el que las comunidades de células son guiadas a adheridas a una superficie y sobre sí mismas, este proceso facilitado por los polímeros secretados. Curiosamente, después de alcanzar una alta densidad celular, algunas especies bacterianas activan la secreción de polímero, mientras que otras la inhiben (7). En la actualidad se reconoce a la placa dental como una biopelícula y a pesar que ser de fácil acceso para su tratamiento, es microbiológicamente muy compleja para tomar a la ligera, por tal motivo, muchos estudios de biopelículas dentales han empleado microscopía electrónica de transmisión y, ocasionalmente, microscopía electrónica de barrido. Otra alternativa que se está utilizando es la de interrumpir el mecanismo QS estudiando de forma experimental y teórica la maquinaria involucrada en el QS para diseñar inhibidores específicos.

Hace poco los autores del presente estudio publicaron un artículo donde se hicieron una variedad de 
cálculos tipo Docking sobre una serie de moléculas análogas a la acil homoserinas lactonas (AHLs) y los reguladores de proteínas LuxR y TraR con el objetivo de entender el complejo microambiente en que diferentes análogos moleculares de la AHL pueden ser expuestos. Se demostró que la actividad antiquórum sensing de estos análogos moleculares depende del anillo lactónico de estos compuestos y de la estequiometría del grupo carbonil $(\mathrm{C}=\mathrm{O})$ y del grupo amino $\left(\mathrm{NH}_{2}\right)$ de las cadenas laterales; todo esto en combinación con los residuos de aminoácidos que se conservan de la familia de proteínas tipo TraR y LuxR, todo eso como parte de diversas estrategias en la búsqueda de opciones de control químico de las biopelículas (8).

\section{QUÉ ES UNA BIOPELÍCULA}

Las biopelículas son comunidades de microorganismos que crecen embebidos en una matriz de exopolisacáridos y adheridos a una superficie inerte o a un tejido vivo. También se definen como una comunidad estructurada de microorganismos inmovilizados, adheridos a una superficie inerte o viva, encapsulados en una matriz polimérica orgánica de origen bacteriano, que representa una forma de crecimiento protegida en un medio hostil. Las comunidades microbianas mantienen una forma de comunicación a través de la detección del quórum, emplean diferentes señales químicas para supervisar su entorno, alterar la expresión genética y obtener ventaja sobre sus competidores. Estas señales pueden ser de AHL, modificadas o sin modificar (9).

\section{EVOLUCIÓN DEL CONCEPTO DE BIOPELÍCULA}

En los últimos 150 años los grandes avances científicos en el campo de la biomedicina permiten a los profesionales de la salud, especialmente a los odontólogos, detectar y tratar enfermedades periodontales de una forma más eficiente de acuerdo a la realidad clínica y microbiológica. Por ejemplo, hoy se tiene la certeza que la gingivitis y periodontitis son infecciones inducidas por las biopelículas, causadas por los componentes de la flora oral indígena, que retan de manera inmunológica al organismo produciendo una respuesta de tipo inflamatoria cuyos componente inmunológicos son los principales responsables de la mayoría de los daños y pérdidas en los tejidos observados tanto a nivel periodontal, así como en otras estructuras del organismo, actuando a larga distancia (10).

En la década de 1970 se descubrió que la comunicación celular de las bacterias puede ser desencadenada por pequeñas moléculas de señalización que se difunden en los espacios intercelulares. La primera evidencia de la comunicación celular en las bacterias se estableció en la bacteria luminiscente Vibrio fischeri ( $V$. fischeri), que establece una relación simbiótica con los organismos de orden superior, como el calamar hawaiano luminoso (Euprymna scolopes). El $V$. fischeri produce un compuesto o señal de difusión, que depende de la concentración acumulada en el medio ambiente durante el crecimiento de las bacterias. En su estado planctónico o de vida libre, las células de $V$. fischeri no presentan luminiscencia, puesto que la concentración de la señal no alcanza el umbral en la densidad de células que se producen en el mar (100 células/ml). Sin embargo, en el órgano de luz de los calamares, donde la densidad de la célula llega a $10^{10}$ o a $10^{11}$ células $/ \mathrm{ml}$, las moléculas de señalización se pueden acumular a una concentración adecuada para activar la luminiscencia (11).

Nealson et al., en el 2006, establecieron que, inicialmente, a pesar de la detección de este tipo de mecanismos, los investigadores no eran conscientes del mecanismo que subyace a la regulación de la bioluminiscencia del $V$. fischeri, que 20 años más tarde se denominó "detección de quórum". El mecanismo se basa en el principio de que, sólo cuando la concentración del autoinductor alcanza un umbral crítico, se le permite a las células percibir una señal y activar o reprimir genes diana en la presencia de un número suficiente de la misma bacteria. A la comunicación celular se le asocia con procesos tales como la bioluminiscencia, la producción de antibióticos, la transferencia de ADN de conjugación, la formación de las biopelículas y la producción de biosurfactante. Las moléculas de señalización implicadas en la comunicación de célula-células son ahora conocidas como autoinductores o moléculas de detección de quórum, su función es la de regular la expresión génica en células de otros organismos de la misma comunidad, que a su vez, realizan el control de una serie de respuestas de las bacterias (12).

Las bacterias que se encuentran en la saliva pueden ser consideradas bacterias planctónicas (bacterias que flotan en una fase líquida). Sin embargo, las bacterias que se encuentran en una superficie dura (diente, reconstrucciones, prótesis e implantes) forman una pe- 
lícula gelatinosa adherente: la placa dental, ésta es el principal agente etiológico de la caries y de las enfermedades periodontales. El concepto y la apariencia de la placa dental presentan variación a lo largo de la historia dependiendo de los medios técnicos disponibles para su estudio (2). Así con la aparición del microscopio óptico, Anthony van Leeuwenhoek observó en 1683 que la placa dental estaba compuesta por depósitos blandos con microbios y restos de comida. Posteriormente en 1898 Black definió la placa dental, como placas blandas gelatinosas (13). En 1965, Egelberg et al., determinaron los estadios en la formación de la placa dental. Estos autores definieron una secuencia o etapas dentro de las que se pueden citar: Un primer estadio o Fase I, en la que se formaría una biopelícula sobre la superficie limpia del diente. Esta biopelícula estaría compuesta fundamentalmente por glicoproteínas. Un segundo estadio o Fase II, en la que se observa la adhesión de unos determinados tipos de bacterias a la biopelícula previamente formada. Fase III, se produce la multiplicación bacteriana. Fase IV, se produce la coagregación de nuevas especies bacterianas. Fase $\mathrm{V}$, crecimiento y maduración de la biopelícula (14). En 1970 en el congreso de periodoncia en Edimburgo, se definió la placa dental como una reunión de microorganismos más los polisacáridos extracelulares; esta placa dental estaba recubierta por leucocitos, células epiteliales y restos de comida. En la década de los noventa, gracias al desarrollo y perfeccionamiento del microscopio láser confocal, se llegó a un mejor conocimiento de la placa dental y de su estructura, lo que permitió el desarrollo del modelo de la placa dental como biopelícula (15).

Desde hace más de 60 años se sugirió que puede existir una conducta bacteriana en grupo, la cual sigue la norma "la unión hace la fuerza". Pero si las bacterias realmente pueden tener una conducta como grupo, entonces se hace necesaria la existencia de un sistema de comunicación entre ellas, a través del cual puedan "votar y decidir" que les conviene y actuar en grupo para conseguirlo. Los análisis recientes basados en las tecnologías genéticas ponen de manifiesto la diversidad de las poblaciones de bacterias dentro de las biopelículas dentales, expresando de manera clara su importante contribución a la salud oral. Durante la primera etapa de formación de las biopelículas, se sabe que las células bacterianas planctónicas se pueden adherir directamente a las superficies de la cavidad oral o indirectamente se unen a otras células bacterianas que colonizaron la superficie. La adhesión a través de la acumulación puede ser crítica para la retención temporal de las bacterias en las superficies dentales y puede facilitar la colonización bacteriana final. Es probable que la comunicación metabólica, el intercambio genético, la producción de factores inhibidores (por ejemplo, bacteriocinas, peróxido de hidrógeno, etc.), sean factores fundamentales que determinan la composición bacteriana de la biopelícula y/o el metabolismo dentro de la nueva estructura u organización (16).

Dado que cada bacteria puede acceder fácilmente a una bacteria vecina y a sus metabolitos, los intercambios genéticos y la comunicación metabólica puede ocurrir con frecuencia dentro de las biopelículas dentales. El QS se define como la regulación génica en respuesta a la densidad celular, que influye en diversas funciones, por ejemplo, la virulencia y la producción de bacteriocinas (17).

Las biopelículas orales son muy heterogéneas en su estructura; se observan las estructuras en forma de setas de alta densidad como las que se originan en la superficie del esmalte, intercaladas con los canales entre los grupos de bacterias, que son espacios libres utilizados como vías de difusión. Los canales están llenos de un polisacárido extracelular (EPS) de la matriz producida por las bacterias (18).

La microscopía de láser confocal confirma que la placa bacteriana tiene una arquitectura abierta con canales y con la presencia de espacios vacíos (19). Las bacterias presentan un patrón alterado de expresión de los genes, ya sea como resultado directo de estar sobre una superficie o indirectamente como una respuesta a la heterogeneidad del medio ambiente local dentro de la biopelícula (20).

\section{FORMACIÓNY ESTRUCTURA DE LAS BIOPELÍCULAS}

La formación de una biopelícula se desarrolla en varias fases y está influenciada por parámetros ambientales e inherentes a la fijación de la célula. Las biopelículas también sirven como nichos de protección para los agentes patógenos. Varios aspectos de la patogenia en humanos están directamente relacionados con el desarrollo de la biopelícula, diversos tipos de superficies en entornos clínicos son propensos a la formación de la biopelícula y por lo tanto puede representar un mayor riesgo para la enfermedad $(19,21)$.

El término biopelícula hace referencia a una serie de microorganismos que se encuentran agregados en un exopolímero compuesto de glicocálix (75\%) y que se 
organizan en forma de colonias adheridas a diferentes superficies, ya sean blandas, animadas e inanimadas (22).

La hidrodinámica juega un papel importante en el desarrollo de la biopelícula, puesto que se desarrolla en una interfase líquido-sólido donde la velocidad del flujo que lo atraviesa influye en el desprendimiento físico de los microorganismos. Además poseen un sistema de canales que les permiten el transporte de nutrientes y desechos, esto resulta de vital importancia cuando se piensa en modificar el ambiente que priva a los microorganismos de las moléculas necesarias para su desarrollo. Otra característica de las biopelículas es su resistencia a las defensas del hospedero y agentes antimicrobianos (23). Mientras que los microorganismos aislados son susceptibles a estos factores de control, las colonias organizadas e incluidas en el exopolímero forman una capa impermeable en donde sólo los microorganismos más superficiales son afectados, permitiendo la supervivencia de la gran mayoría de ellos (24).

Los anticuerpos, las células del sistema inmune y los antimicrobianos no tienen acceso a los microorganismos más profundos, adicionalmente se encuentran en un estado metabólico disminuido, lo que los hace menos susceptible a la acción de estos últimos. También cuando se liberan células de la biopelícula, estas células pueden viajar y depositarse en nuevos nichos de colonización manteniendo las mismas características de una biopelícula adherida a una superficie (25).

Las biopelículas pueden desarrollarse por medio de dos procesos:

- A partir de una célula planctónica, ciertas bacterias tienen la capacidad de desarrollar estructuras de superficie que favorecen la adhesión de las mismas a una superficie sólida, tales como fimbrias y fibrillas. Así los colonizadores primarios como Actinomyces naeslundii, varias especies de estreptococos, como Streptococcus salivarius, Streptococcus parasanguis, Streptococcus mitis, muestran fimbrias y fibrillas en su superficie. Otro factor que favorece la adhesión de las bacterias a una superficie es la capacidad de movimiento de algunas especies, como la Pseudomonas aeruginosa, Pseudomonas fluorescens, Escherichia coli, o la expresión de proteínas en su superficie celular, denominadas adhesinas (26).

- También se pueden desarrollar a partir de células desprendidas de una biopelícula o de partes de la propia biopelícula. En cualquier caso, estas células desprendidas mantendrían todas las propiedades de la biopelícula de donde proceden. También se producen fenómenos de movimiento de la biopelícula sobre la superficie a la que se encuentra adherida $(22,27)$.

Cuando se observa una biopelícula con el microscopio de láser confocal, pueden observarse las distintas comunidades bacterianas organizadas en forma de seta $\circ$ torre y separadas entre sí por microcanales de agua o de fluidos (28). La biopelícula está compuesta por bacterias, que representan un $15-20 \%$ del volumen, una matriz o glicocálix, que representaría el 75\%-80\% (29). Esta matriz puede tener carga neutra o carga polianiónica, según el tipo de exopolisacárido, por lo que pueden interactuar con distintos antimicrobianos, de forma que estos últimos quedan atrapados en la matriz sin capacidad para actuar sobre las bacterias. Además gracias a sus cualidades pueden "modular" la acción de distintos antimicrobianos. La pérdida o alteración de un determinado polisacárido puede alterar la biopelícula, o incluso producirse desaparición (30).

\section{BIBLIOGRAFÍA}

1. Czaran T, Hoekstra RF. Microbial communication, cooperation and cheating: quorum sensing drives the evolution of cooperation in bacteria. PLoS One. 2009;4 (8):e6655.

2. Nowak M, Kurnatowski P. [Biofilm caused by fungistructure, quorum sensing, morphogenetic changes, resistance to drugs]. Wiad Parazytol. 2009;55(1):19-25.

3. Ng WL, Bassler BL. Bacterial Quorum-Sensing Network Architectures. Annu Rev Genet. 2009 Aug 17.

4. Moslehi-Jenabian S, Gori K, Jespersen L. AI-2 signalling is induced by acidic shock in probiotic strains of Lactobacillus spp. Int J Food Microbiol. 2009 Nov 15;135(3): 295-302.

5. Williams P, Camara M. Quorum sensing and environmental adaptation in Pseudomonas aeruginosa: a tale of regulatory networks and multifunctional signal molecules. Curr Opin Microbiol. 2009 Apr;12(2):18291.

6. Duan K, Sibley CD, Davidson CJ, Surette MG. Chemical interactions between organisms in microbial communities. Contrib Microbiol. 2009;16:1-17. 
7. Nadell CD, Xavier JB, Levin SA, Foster KR. The evolution of quorum sensing in bacterial biofilms. PLoS Biol. 2008 Jan;6(1):el4.

8. Ahumedo M, Diaz A, Vivas-Reyes R. Theoretical and structural analysis of the active site of the transcriptional regulators LasR and TraR, using molecular docking methodology for identifying potential analogues of acyl homoserine lactones (AHLs) with anti-quorum sensing activity. Eur J Med Chem. Feb;45(2):608-15.

9. Rinaudi LV, Gonzalez JE. The Low-Molecular-Weight Fraction of the Exopolysaccharide II from Sinorhizobium meliloti is a Crucial Determinant of Biofilm Formation. J Bacteriol. 2009 Sep 25.

10. Siqueira JF, Jr., Rocas IN. Community as the unit of pathogenicity: an emerging concept as to the microbial pathogenesis of apical periodontitis. Oral Surg Oral Med Oral Pathol Oral Radiol Endod. 2009 Jun;107(6):870-8.

11. Fuqua C, Greenberg EP. Self perception in bacteria: quorum sensing with acylated homoserine lactones. Curr Opin Microbiol. 1998 Apr; 1(2):183-9.

12. Nealson $\mathrm{KH}$, Hastings JW. Quorum sensing on a global scale: massive numbers of bioluminescent bacteria make milky seas. Appl Environ Microbiol. 2006 Apr;72 (4):2295-7.

13. Lebedeva MN. [300 years of studies of microscopic organisms (on the 250th death anniversary of Anthony van Leeuwenhoek]. Klin Med (Mosk). 1974 Nov;52(11): 144-6.

14. Egelberg J. Local Effect of Diet on Plaque Formation and Development of Gingivitis in Dogs. 3. Effect of Frequency of Meals and Tube Feeding. Odontol Revy. 1965;16:50-60.

15. Schaudinn C, Gorur A, Keller D, Sedghizadeh PP, Costerton JW. Periodontitis: an archetypical biofilm disease. J Am Dent Assoc. 2009 Aug; 140(8):978-86.

16. Bobrov AG, Bearden SW, Fetherston JD, Khweek AA, Parrish KD, Perry RD. Functional quorum sensing systems affect biofilm formation and protein expression in Yersinia pestis. Adv Exp Med Biol. 2007;603:178-91.

17. Praneenararat T, Geske GD, Blackwell HE. Efficient synthesis and evaluation of quorum-sensing modulators using small molecule macroarrays. Org Lett. 2009 Oct $15 ; 11(20): 4600-3$
18. Dunny GM, Brickman TJ, Dworkin M. Multicellular behavior in bacteria: communication, cooperation, competition and cheating. Bioessays. 2008 Apr;30(4): 296-8.

19. Walker TS, Bais HP, Deziel E, Schweizer HP, Rahme LG, Fall R, et al. Pseudomonas aeruginosa-plant root interactions. Pathogenicity, biofilm formation, and root exudation. Plant Physiol. 2004 Jan;134(1):320-31.

20. Lembke C, Podbielski A, Hidalgo-Grass C, Jonas L, Hanski E, Kreikemeyer B. Characterization of biofilm formation by clinically relevant serotypes of group $A$ streptococci. Appl Environ Microbiol. 2006 Apr;72(4): 2864-75.

21. Ren D, Sims JJ, Wood TK. Inhibition of biofilm formation and swarming of Escherichia coli by (5Z)-4-bromo-5(bromomethylene)-3-butyl-2(5H)-furanone. Environ Microbiol. 2001 Nov;3(1 1):731-6.

22. Zhang $\mathrm{K}, \mathrm{Ou} \mathrm{M}$, Wang W, Ling J. Effects of quorum sensing on cell viability in Streptococcus mutans biofilm formation. Biochem Biophys Res Commun. 2009 Feb 20;379(4):933-8.

23. Kjelleberg $\mathrm{S}, \mathrm{Molin} \mathrm{S}$. Is there a role for quorum sensing signals in bacterial biofilms? Curr Opin Microbiol. 2002 Jun;5(3):254-8.

24. Janakiraman V, Englert D, Jayaraman A, Baskaran H. Modeling growth and quorum sensing in biofilms grown in microfluidic chambers. Ann Biomed Eng. 2009 Jun;37(6):1206-16.

25. Calle GR, Vargas IT, Alsina MA, Pasten PA, Pizarro GE. Enhanced copper release from pipes by alternating stagnation and flow events. Environ Sci Technol. 2007 Nov 1;41(21):7430-6.

26. Ali SA, Benitez JA. Differential response of Vibrio cholerae planktonic and biofilm cells to autoinducer 2 deficiency. Microbiol Immunol. 2009 Oct;53(10):582-6.

27. Yoshida A. [Molecular genetic analysis for oral biofilm formation]. Nippon Saikingaku Zasshi. 2007 May;62(2): 263-9.

28. Kendall MM, Sperandio V. Quorum sensing by enteric pathogens. Curr Opin Gastroenterol. 2007 Jan;23(1):10-5.

29. Halwani M, Hebert S, Suntres ZE, Lafrenie RM, Azghani AO, Omri A. Bismuth-thiol incorporation enhances 
biological activities of liposomal tobramycin against bacterial biofilm and quorum sensing molecules production by Pseudomonas aeruginosa. Int J Pharm. 2009 May 21;373(1-2):141-6.

30. Rasmussen TB, Givskov M. Quorum sensing inhibitors: a bargain of effects. Microbiology. 2006 Apr;152(Pt 4):895-904.

\section{CORRESPONDENCIA}

Antonio José Díaz Caballero

Facultad de Odontología. Universidad de Cartagena Campus de la salud. Barrio Zaragocilla

Cartagena de Indias. Colombia

Correo electrónico: antoniodiazc@yahoo.com, adiazcl@unicartagena.edu.co 